Daria Gunina - Vladislav Bina - Michal Novak*

\title{
STRATEGIC ADVERTISING MANAGEMENT: THE CASE OF THE TRANSPORTATION AND STORAGE MARKET IN THE CZECH REPUBLIC
}

The aim of this study is to analyse the advertising strategy on the transportation and storage market in the Czech Republic. The study provides information and knowledge of seasonal advertising scheduling by answering three research questions. The statistical analysis is based on a research sample of 840,204 advertisements aired in 2013-2017. The results of the study show different scheduling patterns of subcategories in the transportation and storage market. They also point out that subcategories in the transportation and storage NACE category are different. Therefore, marketing researchers should take this knowledge into account in their generalisations.

Keywords: commercials, mass media, communication strategy, transport

\section{Introduction}

Strategic advertising management includes such activities as advertising planning, organising and decision-making for achieving the set strategic goals [1], [2], [3]. It attempts to solve the problem of how to effectively deliver the message to potential consumers through media [4]. Thus, the media plan should provide a clear schedule of what (product) to advertise, when (date, hour) and where (media type, medium). Media plan suitability can significantly influence advertising effectiveness as it can influence companies' brand image, brand attitude, sales, and other indicators of success such as company performance [5], [6]. Hence, the media plan is an important pillar of advertising success and this issue deserves more in-depth attention and should not be underestimated.

The motivation of this study is to contribute to the debate on marketing in the transport industry and to analyse advertising strategy on the transportation and storage market in the Czech Republic. As the transportation market provides services, so transport marketing differs from manufacturing marketing [7]. Companies on this market should deploy a marketing campaign to gain a competitive advantage, attract potential customers, and retain regular customers [8]. The transportation market targets many different consumer segments [8] according to their age, economic situation, and lifestyle.

This study focuses on different subcategories of the transportation and storage market as consumer behaviour [8] and advertising activity in subcategories may differ. The transportation and storage market in the Czech Republic is divided into subcategories: Air transport; Other post and courier services; Post and courier services; Land and pipeline transport; Land and personal transport; Road freight transport; Storage; Storage and subsidiary transport; Subsidiary transport activities; Inland shipping; Railroad transport; Sea and seashore shipping; Shipping; Pipeline transport. Different types of transport tend to compete. For example, with the rise of private cars, the demand for public transport decreases [9]. Such circumstances force the transportation market not only to optimise the supply [10] or search for non-traditional solutions [11] but also to study its consumers' behaviour [9], [12], [13], to promote its offer [8], [14], [15], to improve communication between consumers and service providers [16], [17], [18], and to be market-oriented [19]. For example, advertising (along with other marketing activities) in Perth (Scotland) helped public transport to increase the number of passengers [8].

Forms of media plans and general advertising activities differ depending on the industries or product categories [20]. In particular, these stem from the nature of the product. For example, low-involvement and high-involvement products require using different media types and diverse timing [2]. This is also related to different seasonality [21], [22]. Some products (e.g. groceries) tend to be bought at the end of a workweek; some products (e.g. gym membership) sell more at the beginning of a year [5]. Also, some products (e.g. flight tickets, shoes) have a higher demand in the middle of the month following payday. Advertising seasonal patterns precede the industry peak in one or two months to reach the consumer in time [2]. Seasonal patterns can also be found in dayparts as different shows in different daytimes can reach different audiences [5]. This is one the reasons why some advertisements tend to be aired in different dayparts. This all reveals the background for posing the following research questions regarding the transportation industry in order to find such patterns:

- RQ1: "Is there a seasonal component in the advertising activity (during the year) on the Czech transportation market?"

- RQ2: "Is there a correlation between the advertising activity of different categories of transportation and storage on the Czech market?"

- RQ3: "Is there a seasonal component in the advertising activity (during the day) on the Czech transportation market?"

\footnotetext{
* Daria Gunina, Vladislav Bina, Michal Novak

Faculty of Management, University of Economics in Prague, Jindrichuv Hradec, Czech Republic

E-mail: daria.gunina@vse.cz
} 
Table 1 Research sample: number of ads on TV, radio, and print in particular subcategories

\begin{tabular}{|c|c|c|c|c|c|}
\hline & 2013 & 2014 & 2015 & 2016 & 2017 \\
\hline Air transport & 41,035 & 31,732 & 45,647 & 45,963 & 45,603 \\
\hline Other post and courier services & 677 & 10,244 & 2,975 & 5,055 & 2,114 \\
\hline Post and courier services & 4,240 & 2,850 & 1,423 & 2,363 & 1,021 \\
\hline Land and pipeline transport & 15 & 450 & 464 & 130 & 2,793 \\
\hline Land and personal transport & 22,160 & 27,582 & 21,222 & 20,942 & 26,504 \\
\hline Road freight transport & 2,136 & 3,833 & 8,118 & 4,852 & 5,559 \\
\hline Storage & 24 & 5 & 21 & 14 & 113 \\
\hline Storage and subsidiary transport & 521 & 558 & 734 & 1,730 & 1,817 \\
\hline Subsidiary transport activities & 52,360 & 92,088 & 103,699 & 79,096 & 50,075 \\
\hline Inland shipping & 837 & 584 & 1,347 & 896 & 928 \\
\hline Railroad transport & 10,004 & 7,335 & 7,410 & 14,882 & 22,256 \\
\hline Sea and seashore shipping & 14 & 287 & 53 & 25 & 17 \\
\hline Shipping & 5 & 39 & 166 & 267 & 294 \\
\hline Pipeline transport & 1 & 0 & 0 & 0 & 0 \\
\hline
\end{tabular}

\section{Research design and methodology}

This research analyses the mass media market data for the Czech Republic obtained by media monitoring by the Nielsen Admosphere research agency in the NACE "Transportation and Storage" category. The research sample contains data on all advertising messages on television $(174,503)$, radio $(620,797)$, and print $(44,904)$ in 2013-2017. The analysis does not include online media as the volumes of Internet advertising and investment in it are difficult to measure. The research is based primarily on quantitative quasi-experiment methods. The whole research sample contains 840,204 advertisements aired in the years 20132017. The research sample divided into NACE subcategories is shown in Table 1.

Since the data file contains data concerning all advertising messages on television, radio and print, it is sufficient to use the descriptive means of statistics. There is no straightforward possibility to generalise the results within the scope of the Czech Republic and the analysed timeframe. Therefore, it is not reasonable to employ means of mathematical statistics such as hypothesis testing or interval estimates.

The statistical software R 3.4.3 [23] was used for statistical analysis and the depiction of data. Various statistical methods were used for the data analysis. The methods used are introduced in the following text according to the research questions.

To answer the first research question (RQ1), the seasonal components of the monthly time series of the advertisement count in different categories are computed using the seasonal decomposition of the time series by LOESS smoothing [24] (a locally weighted polynomial regression). In this procedure, the seasonal values are removed and the remainder is smoothed to find the trend. The overall level is removed from the seasonal component and added to the trend component. This process is iterated a few times.

To answer the second research question (RQ2), the seasonal components calculated by the LOESS smoothing procedure are further analysed using a correlation matrix containing Pearson correlation coefficients. The graphical display approach of Murdoch and Chow [25] is used for the graphical representation.

To answer the third research question (RQ3), the time of advertisement broadcasting (hour-minute-second) was categorised into a daypart. Katz [5] defines nine dayparts for the American market. As the Czech media market differs from the American market, we defined the dayparts according to media habits in the Czech Republic using the following categories: Late night (23:00:00-00:59:59), Dead time (1:00:00-5:59:59), Early morning (6:00:00-8:59:59), Daytime (9:00:00-11:59:59), Early fringe (12:00:00-16:59:59), Evening (17:00:00-18:59:59) and Primetime (19:00:00-22:59:59). Since we are analysing the time of the day, we use only data concerning advertisements on TV and Radio. Therefore, the analysis is based on a two-dimensional contingency table of the counts of advertisements, in particular, the categories according to the categorised time of the day.

\section{Findings and discussion}

The findings are divided into three sections according to the formulated research questions.

\subsection{RQ1 - Seasonal components in advertising activity (during the year)}

Figure 1 shows the seasonal components of a monthly series of advertisement counts in 14 NACE categories. According to the visualised graphs, one can conclude that there are seasonal components in the advertising activity (during the year) on the Czech transportation market. It is evident that a substantial difference in the particular month counts exists in all the categories. A decrease can be frequently observed in the summer period or an increase during autumn - as in the subcategories Air transport, Post and courier services, and Land personal transport. Contrary to these observations, a rise can be observed in advertising activity during the summer in the subcategories 

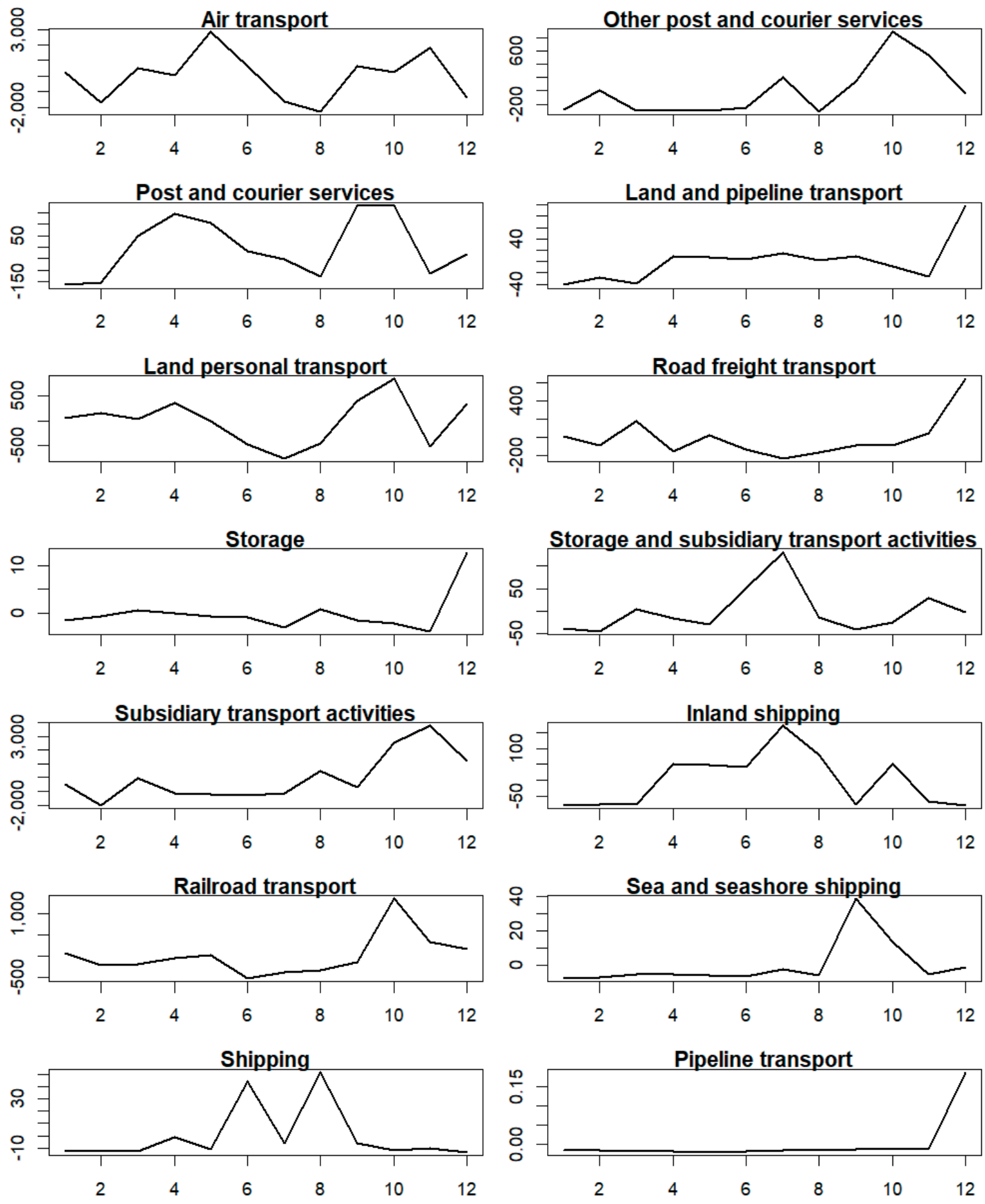

Figure 1 Seasonal components of the monthly series of advertisement counts in different categories

Shipping, Other post and courier services, Inland shipping and Storage and subsidiary transport activities. Some subcategories also have a strong seasonal component for a few months before the end of a year - e.g. Other post and courier services, Road freight transport, Storage, and Subsidiary transport activities. In terms of the transportation of people - Air transport, Land personal transport and Railroad transport, it can be observed that these three subcategories have different seasonal advertising trends.
3.2 RQ2 - Advertising activity of different transportation and storage categories

As can be seen in Figure 1, the advertising activity in some categories of transportation and storage branches show common patterns. Therefore, it is reasonable to conduct a correlation analysis to find which categories show related behaviour. This is in the correlation plot of the seasonal components of the monthly time series (Figure 2). 


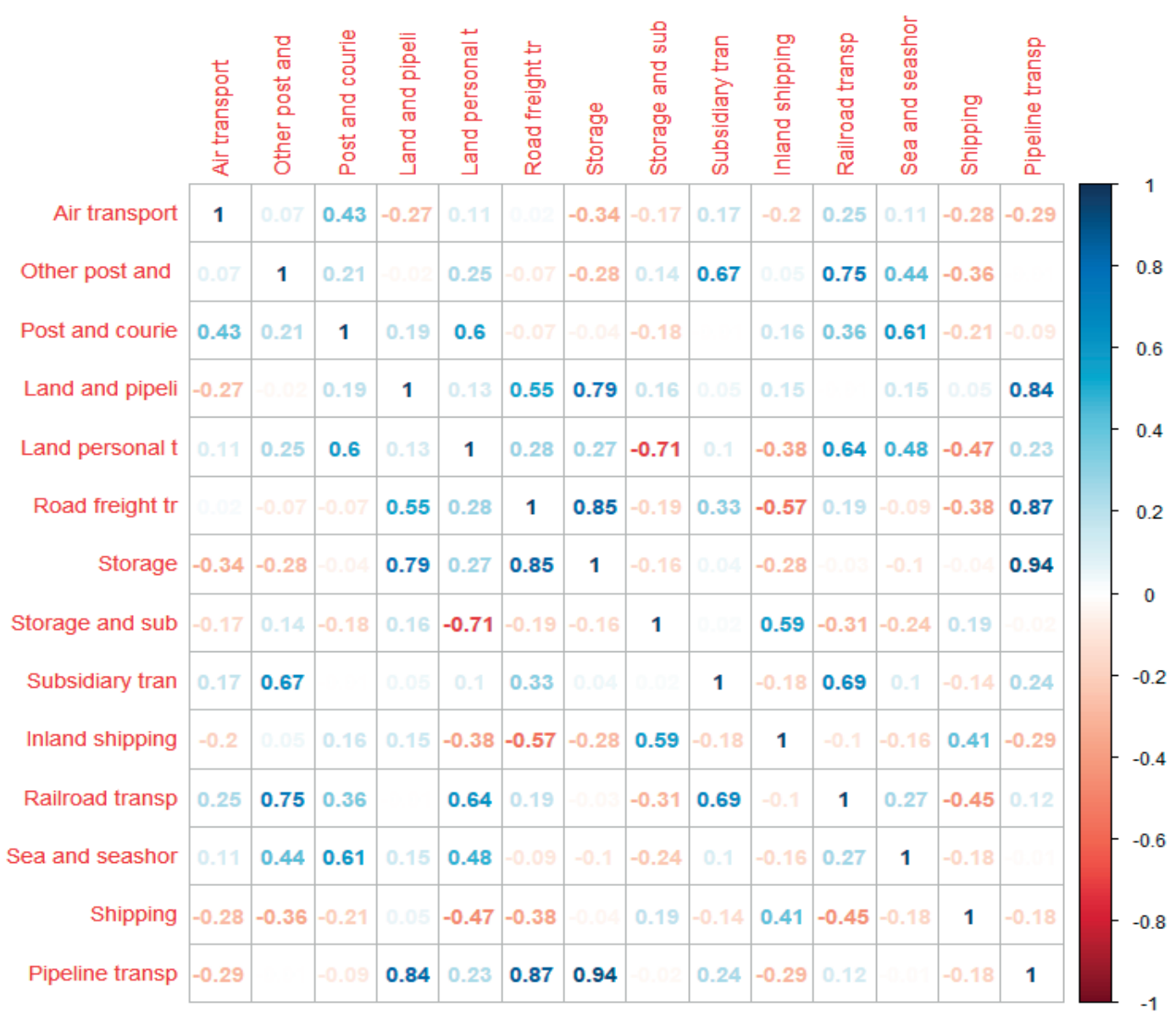

Figure 2 Correlation plot of seasonal components of the monthly time series in the transport branches

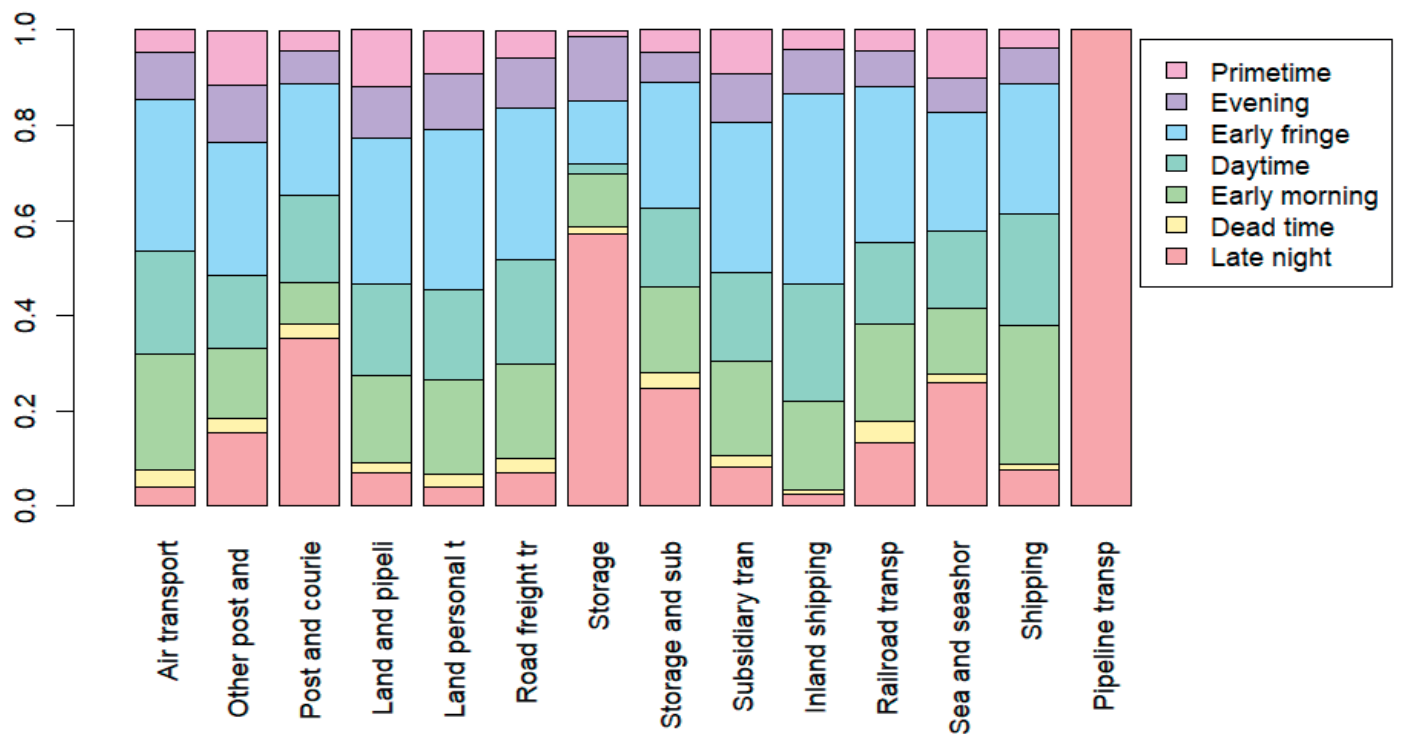

Figure 3 Frequencies of advertisements in particular NACE categories during the day from Monday to Friday

It can be observed that the Air transportation somehow has a unique seasonal component. It has a weak correlation (0.11) with the Land personal transportation and Railroad transportation $(0.25)$. However, the correlation between the
Land personal transportation and Railroad transportation has a stronger correlation (0.64). One can conclude that the air transport segment on the Czech market has a different seasonality than the railroad and land transportation segments. 


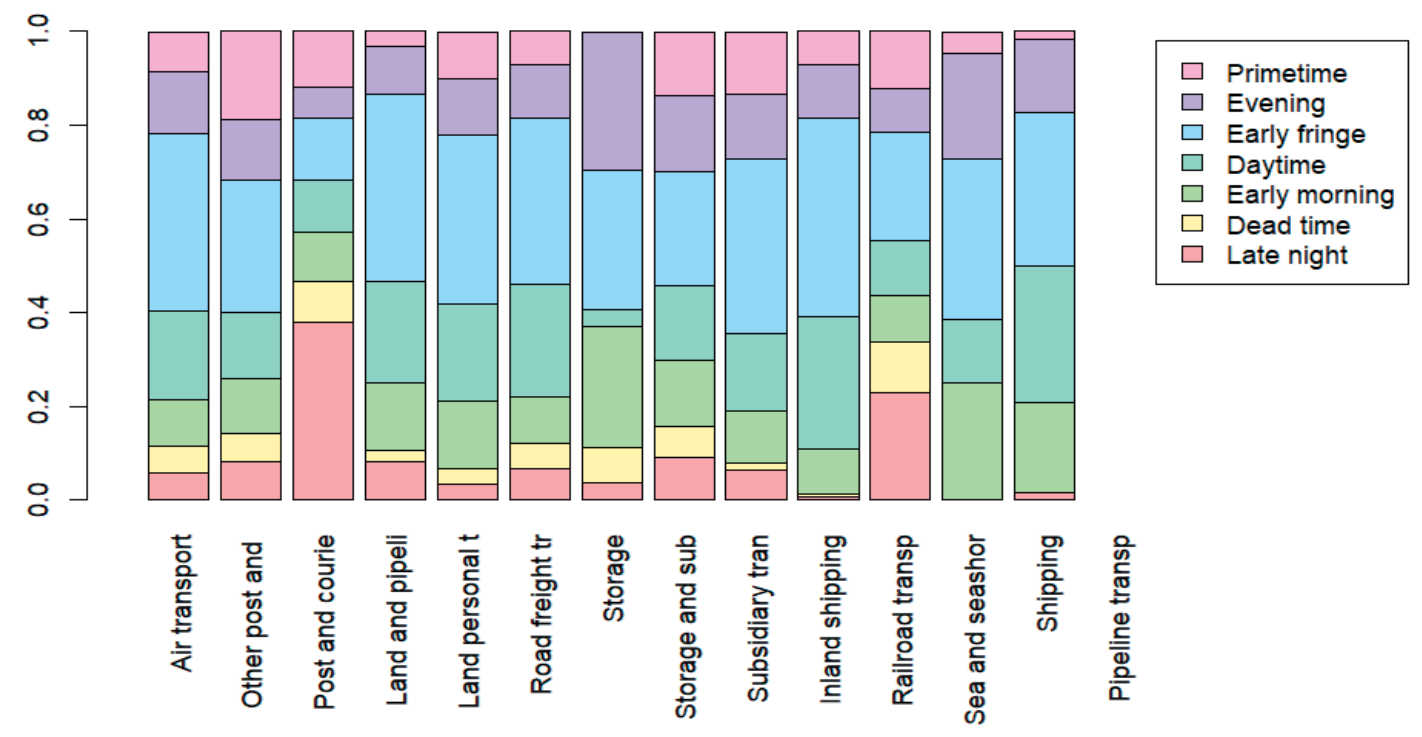

Figure 4 Frequencies of advertisements in particular NACE categories during the day during the weekends

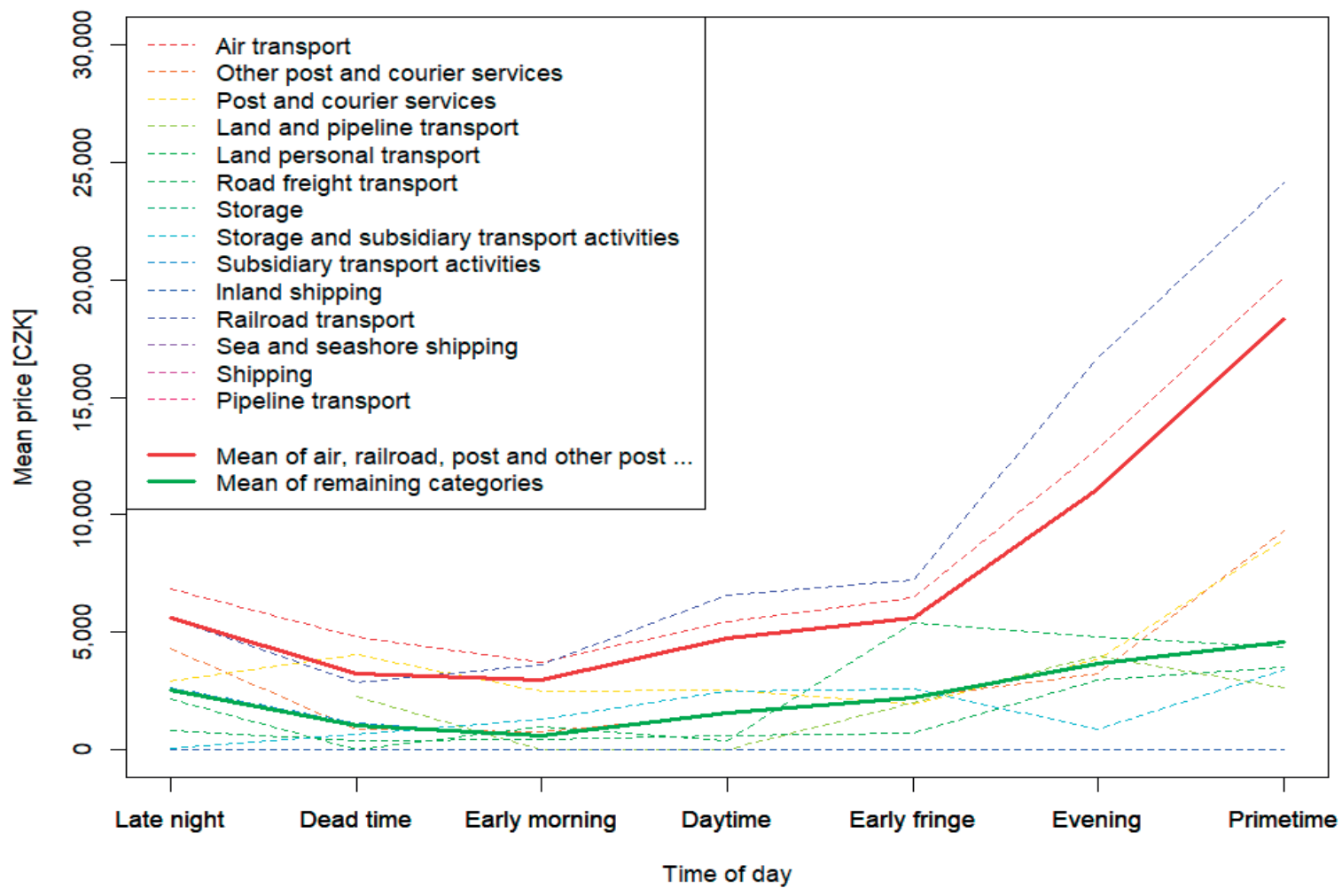

Figure 5 Mean prices of TV advertisements during the daytime

\subsection{RQ3 - Seasonal components in advertising activity (during the day)}

The frequency of appearance of advertisements on TV and radio during the day appears to be different for some subcategories. In Figure 3 and Figure 4, one can see that advertising during the daytime differs not only in particular subcategories but during the working days and weekends, as well. In terms of personal transportation, the Land personal transport uses more primetime advertising on weekdays than Air transport or Railroad transport. However, during the weekends it is the Railroad transport which uses most primetime in terms of personal transportation.

The strategy concerning advertising also substantially differs in different media. In Figure 5 and Figure 6, one can see different mean prices of advertisements during the daytime. It is quite understandable that the highest prices appear in the case of TV during the evening and in primetime, although there are categories for which this effect is stronger - namely those 


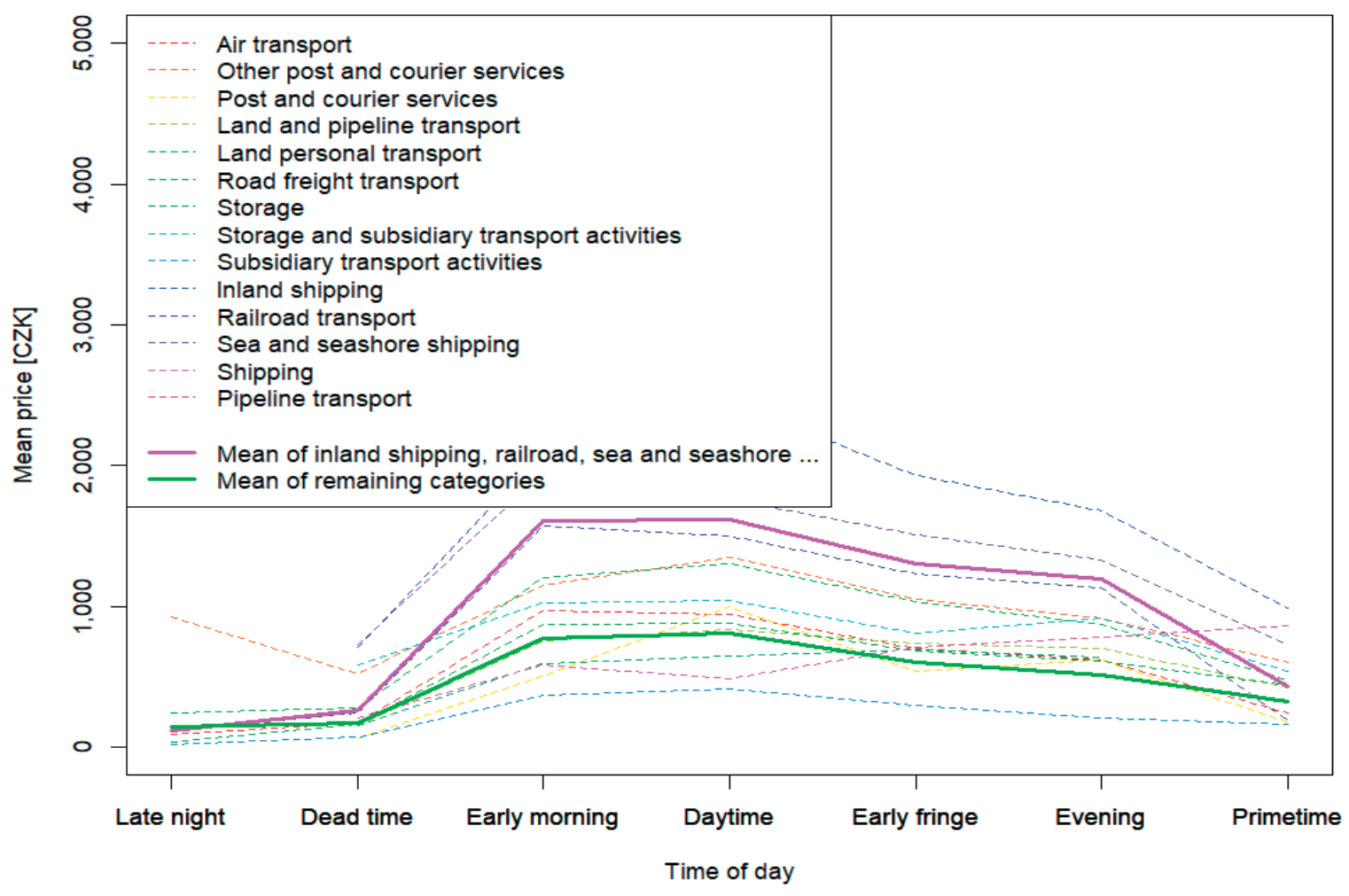

Figure 6 Mean prices of radio advertisements during the daytime

categories concerning air and railroad transport together with post and related services. On the contrary, in the case of the radio advertisements, a peak during the early morning and daytime (i.e., working hours) can be observed. Again, the peak is more substantial in the case of the shipping and railroad transport categories.

\section{Conclusion}

This study aimed to analyse advertising strategy on the transportation and storage market in the Czech Republic. The research sample was 840,204 advertisements aired in the Czech Republic in 2013-2017. Results show that particular NACE subcategories in the transportation and storage market evince a difference in advertising strategy. Naturally, different transportation types (i.e. NACE subcategories) compete with each other [8], [9], [19]. Nevertheless, on the advertising market, they appear to follow diverse goals, target different audiences, and deploy different advertising strategies. The analysis revealed the expected [5] advertising seasonality on the transportation and storage market either in months or parts of the day.

Such a conclusion contributes to the debate on marketing in the transport industry. The study also provides various managerial implications. It provides useful information and knowledge about seasonal advertising scheduling not only for media practitioners but also for managers in the transportation market. Ultimately, this study provides an overview of the transportation and storage market in the Czech Republic and emphasises the role of advertising competition in subcategories. The recommendation for advertisers is to monitor the competitors advertising strategy only in a particular subcategory rather than the entire transportation market.

This study has several research limitations. It analyses only one industry (transportation) and generalisations on other industries cannot be made. In addition, the study focused only on traditional media types: the research sample consists only of commercials in the TV, radio and print media. The Internet as a decentralised medium is not taken into account. In this case, non-studied new and alternative media provide a gap for further research extension.

Moreover, possible delays in reactions between variables are not considered. This presents significant opportunities for further research. The study could be extended by comparing different industries on the first NACE level or by comparing the results from the Czech Republic with those of different countries.

\section{Acknowledgements}

This study was supported by the Internal Grant Agency project of the University of Economics, Prague IGS F6/01/2018. 


\section{References}

[1] ARENS, W. F., BOVEE, C. L.: Contemporary Advertising. McGraw-Hill Education, 1994.

[2] PERCY, L., ROSENBAUM-ELliOTT, R.: Strategic Advertising Management, $5^{\text {th }}$ ed. Oxford University Press, 2016.

[3] GOLOB, U., PODNAR, K.: Advertising Decision Makers' and Consumers' Perceptions of Media Substitutability. Journal of Promotion Management, 21(6), 798-816, 2015. https://doi.org/10.1080/10496491.2015.1088923

[4] AAKER, D. A., MYERS, J. G., BATRA, R.: Advertising Management. Englewood Cliffs, N.J Prentice Hall, 1992.

[5] KATZ, H.: The Media Handbook: A Complete Guide to Advertising Media Selection, Planning, Research, and Buying, $6^{\text {th }}$ ed. New York: Taylor \& Francis, 2017.

[6] TELLIS, G. J.: Effective Advertising: Understanding When, How, and Why Advertising Works. SAGE Publications, Marketing for a New Century, 2003.

[7] KRIZANOVA, A., HRIVNAK, M.: Supply in Marketing Process of Road Transport. Communications - Scientific Letters of the University of Zilina, 7(2), 13-16, 2005.

[8] IBRAEVA, A., DE SOUSA, J. F.: Marketing of Public Transport and Public Transport Information Provision. Procedia-Social and Behavioral Sciences, 162, 121-128, 2014. https://doi.org/10.1016/j.sbspro.2014.12.192

[9] KAMPF, R., LIZBETIN, J., LIZBETINOVA, L.: Requirements of a Transport System User. Communications - Scientific Letters of the University of Zilina, 14(4), 106-108, 2012.

[10] CERNY, J., CERNA, A., LINDA, B.: Support of Decision-Making on Economic and Social Sustainability of Public Transport. Transport, 29(1), 59-68, 2014. https://doi.org/10.3846/16484142.2014.897645

[11] CERNA, A., CERNY, J.: A Note to Non-Traditional Systems of Public Transport. Communications - Scientific Letters of the University of Zilina, 7(1), 64-66, 2006.

[12] CANTWell, M., CAUlfield, B., O’MAHONY, M.: Examining the Factors that Impact Public Transport Commuting Satisfaction. Journal of Public Transportation, 12(2), 1-21, 2009. http://doi.org/10.5038/2375-0901.12.2.1

[13] URBANEK, A.: Big Data - A Challenge for Urban Transport Managers. Communications - Scientific Letters of the University of Zilina, 19(2), 36-42, 2017.

[14] FRAMPTON, N.: Changing the Image of Public Transport through Marketing. Logistics \& Transport Focus, 9(8), 15-18, 2007.

[15] KLEMENTSCHITZ, R., ROIDER, O.: Active Measures as Part of Dialogue Marketing Promoting the Use of Public Transport in Rural Areas. Transport Problems: An International Scientific Journal, 10(4), 57-74, 2015. http://doi.org/10.21307/tp-2015-048

[16] DRDLA, P., HRABACEK, J.: Website Contents of Municipal Transport Undertaking as a Modern Communication Tool for Enhancing Quality of Transport Services. Communications - Scientific Letters of the University of Zilina, 7(2), 46-48, 2005.

[17] MCGOVERN, E.: Transport Behavior: A Role for Social Marketing. Journal of Nonprofit \& Public Sector Marketing, 17(1-2), 121-134, 2007. https://doi.org/10.1300/J054v17n01_06

[18] PENDER, B., CURRIE, G., DELBOSC, A., SHIWAKOTI, N.: Social Media Use during Unplanned Transit Network Disruptions: a Review of Literature. Transport Reviews, 34(4), 501-521, 2014. https://doi.org/10.1080/01441647.2014.915442

[19] MOLANDER, S., FELlESSON, M., FRIMAN, M., SKÅLEN, P.: Market Orientation in Public Transport Research - A Review. Transport Reviews, 32(2), 155-180, 2012. https://doi.org/10.1080/01441647.2011.633248

[20] GUNINA, D., KINCL, T., SULDOVA, S.: Usage of Colors in TV Commercials: Cross-Industry Analysis of Mass Media Communications. Communications - Scientific Letters of the University of Zilina, 19(4), 64-71, 2017.

[21] GENESOVE, D., SIMHON, A.: Seasonality and the Effect of Advertising on Price. The Journal of Industrial Economics, 63(1), 199-222, 2015. https://doi.org/10.1111/joie.12067

[22] KIYGI-CALLI, M., WEVERBERGH, M., FRANSES, P. H.: Modeling Intra-Seasonal Heterogeneity in Hourly AdvertisingResponse Models: Do Forecasts Improve? International Journal of Forecasting, 33(1), 90-101, 2017. https://doi.org/10.1016/j. ijforecast.2016.06.005

[23] R CORE TEAM: R: A Language and Environment for Statistical Computing [online]. R Foundation for Statistical Computing, 2017. Available: https://www.r-project.org/ [accessed 2018-05-26].

[24] CLEVELAND, W. S., DEVLIN, S. J.: Locally Weighted Regression: An Approach to Regression Analysis by Local Fitting. Journal of the American Statistical Association, 83(403), 596-610, 1988. https://doi.org/10.1080/01621459.1988.10478639

[25] MURDOCH, D. J., CHOW, E. D.: A Graphical Display of Large Correlation Matrices. The American Statistician, 50(2), 178-180, 1996. https://doi.org/10.1080/00031305.1996.10474371 